\title{
Article \\ Precipitation Dominates the Relative Contributions of Climate Factors to Grasslands Spring Phenology on the Tibetan Plateau
}

\author{
Min Cheng ${ }^{1,2}\left(\mathbb{D}\right.$, Ying Wang ${ }^{3, * \mathbb{C}}$, Jinxia Zhu ${ }^{1,2}$ and Yi Pan ${ }^{1,2}$ \\ 1 Institute of Land and Urban-Rural Development, Zhejiang University of Finance and Economics, \\ Hangzhou 310018, China; chengmin@zufe.edu.cn (M.C.); jxzhu@zufe.edu.cn (J.Z.); \\ ypangis@zufe.edu.cn (Y.P.) \\ 2 Zhejiang Institute of "Eight-Eight" Strategies, Hangzhou 310018, China \\ 3 School of Culture Industry and Tourism Management, Sanjiang University, Nanjing 210012, China \\ * Correspondence: wang_ying@sju.edu.cn
}

Citation: Cheng, M.; Wang, Y.; Zhu, J.; Pan, Y. Precipitation Dominates the Relative Contributions of Climate Factors to Grasslands Spring Phenology on the Tibetan Plateau. Remote Sens. 2022, 14, 517. https://doi.org/10.3390/rs14030517 Academic Editors: Ruyin Cao, Miaogen Shen and Bin Fu

Received: 8 December 2021 Accepted: 20 January 2022 Published: 21 January 2022

Publisher's Note: MDPI stays neutral with regard to jurisdictional claims in published maps and institutional affiliations.

Copyright: (C) 2022 by the authors. Licensee MDPI, Basel, Switzerland. This article is an open access article distributed under the terms and conditions of the Creative Commons Attribution (CC BY) license (https:// creativecommons.org/licenses/by/ $4.0 /)$.

\begin{abstract}
Temperature and precipitation are the primary regulators of vegetation phenology in temperate zones. However, the relative contributions of each factor and their underlying combined effect on vegetation phenology are much less clear, especially for the grassland of the Tibetan Plateau To quantify the contribution of each factor and the potential interactions, we conducted redundancy analysis for grasslands spring phenology on the Tibetan Plateau during 2000-2017. Generally, the individual contribution of temperature and precipitation to grasslands spring phenology (the start of growing season (SOS)) was lower, despite a higher correlation coefficient, which further implied that these factors interact to affect the SOS. The contributions of temperature and precipitation to the grasslands spring phenology varied across space on the Tibetan Plateau, and these spatial heterogeneities can be mainly explained by the spatial gradient of long-term average precipitation during spring over 2000-2017. Specifically, the SOS for meadow was dominated by the mean temperature in spring $\left(\mathrm{T}_{\text {spring }}\right)$ in the eastern wetter ecoregion, with an individual contribution of $24.16 \%(p<0.05)$, while it was strongly negatively correlated with the accumulated precipitation in spring $\left(\mathrm{P}_{\text {spring }}\right)$ in the western drier ecoregion. Spatially, a $10 \mathrm{~mm}$ increase in long-term average precipitation in spring resulted in an increase in the contribution of $\mathrm{T}_{\text {spring }}$ of $2.0 \%(p<0.1)$ for meadow, while it caused a decrease in the contribution of $\mathrm{P}_{\text {spring }}$ of $-0.3 \%(p<0.05)$. Similarly, a higher contribution of $\mathrm{P}_{\text {spring }}$ for steppe was found in drier ecoregions. A spatial decrease in precipitation of $10 \mathrm{~mm}$ increased the contribution of $\mathrm{P}_{\text {spring }}$ of $1.4 \%(p<0.05)$. Considering these impacts of precipitation on the relative contribution of warming and precipitation to the SOS, projected climate change would have a stronger impact on advancing SOS in a relatively moist environment compared to that of drier areas. Hence, these quantitative interactions and contributions must be included in current ecosystem models, mostly driven by indicators with the direct and the overall effect in response to projected climate warming.
\end{abstract}

Keywords: climate change; spring phenology; individual contribution; interacting effects; Tibetan Plateau

\section{Introduction}

Climate change was now documented in all major regions of the world and affected vegetation structure and function as well as public health [1-4]. As the dominant vegetation type on the Tibetan Plateau, grassland plays important roles in ecological balance and provides an important buffer against climate change [5,6], and the grassland phenology was identified as a key indicator of climate-vegetation interactions and reflects the response of living systems to climate change $[7,8]$. In particular, the spring phenology of grassland can provide insight into higher level dynamics of plant functioning and feedback to climate change through exchange of energy, the hydrological cycle, and carbon uptake, which is more relevant to global climate and regional natural environmental changes [9-13]. 
Temperature and precipitation are regarded as the primary regulators of plant phenology in the temperate zone. Highly credible evidence shows that global warming and regional changes in precipitation strongly affected vegetation phenology [12,14-17]. Although there were many studies focused on understanding the mechanisms and influences of climate warming and regional precipitation on vegetation phenology, there are still a lot of uncertainties in the responses of the start of growing season (SOS) to these factors. As proof, Lucht et al. [18] and Xu et al. [19] showed that the growth of vegetation would be facilitated, because global warming eased climatic constraints. However, according to Jeong et al. [20], the vegetation spring phenology and preseason mean temperature are correlated across the Northern Hemisphere with a correlation coefficient varying from -0.3 to -0.7 , suggesting that global warming would not necessarily induce greater advance in SOS. In addition, Yu et al. [13] showed that winter warming could delay vegetation spring phenology due to the adaptive ability of chilling requirements, while Suonan et al. [21] showed that winter warming increased the soil temperature, and then advanced spring leaf out and flowering phenology. Some studies also showed that the daylength could coregulate the SOS through its interaction with temperature or its influence on the stomata aperture and photosynthetic active radiation [22,23]. Furthermore, water is also necessary for plant growth, which indicates that changes in regional precipitation should be another main driving factor that regulate vegetation phenology, particularly in water-limited areas $[9,12,16,24]$. However, the SOS's responses to preseason precipitation were also diverse. Dai et al. [25] found that precipitation and the first leafing date do not show a significant negative correlation. Other studies, on the other hand, reported that, in arid or semiarid regions, preseason precipitation indeed advanced vegetation SOS because it determines spring water availability $[5,9,26]$. Moreover, some studies argued that preseason precipitation would increase the heat demand and then influence the sensitivity of SOS to precipitation and temperature $[16,27]$. That is, along with direct impact, precipitation may exert indirect impacts on SOS. These direct and indirect impacts indicated that temperature and precipitation would complicatedly interact to affect vegetation SOS. It is difficult to quantify the individual contributions of temperature and precipitation to the interannual variation of vegetation phenology because of the nonlinear impacts and underlying interactions of climate factors.

As the world's largest plateau, the Tibetan Plateau is considered as one of the most vulnerable ecosystems because of its typical alpine climate and its strong sensitivity to climate change [5,9-13]. Although numerous recent studies reported the interannual variation of SOS and its responses to warming and precipitation [10-13,28], large uncertainties still exist about the advanced (i.e., earlier) or delayed (i.e., later) pattern of the vegetation spring phenology and their responses to different factors. For instance, Piao et al. [29] showed that the spring phenology of alpine meadow would be delayed by the increased accumulated preseason precipitation occurring in five months before the vegetation onset, while Shen et al. [30] found that declines in spring precipitation would delay SOS rather than increase preseason precipitation. Moreover, Yu et al. [13] showed that winter warming could delay grassland spring phenology on the Tibetan Plateau, while Suonan et al. [21] showed that asymmetric winter warming advanced plant phenology in alpine meadow. Furthermore, these explanations were later questioned by some studies that argued that the vegetation spring phenology was more strongly affected by the interaction of warming and precipitation than the unitary effect of driving factors $[5,9,11,16]$. Even so, the interaction effects of climate factors on vegetation phenology remain poorly understood, and the individual contribution of each factor to grassland SOS across the Tibetan Plateau is not yet well understood. Thus, quantitative estimation of the relative contribution of critical climate factors and their interaction effects on grassland SOS on the Tibetan Plateau is critical and valuable. In this study, we first analyze how SOS changed in the grassland in different ecoregions of the Tibetan Plateau. We untangle the individual contribution and interaction of the mean temperature in winter $\left(\mathrm{T}_{\text {winter }}\right)$, mean temperature in spring $\left(\mathrm{T}_{\text {spring }}\right)$, and the accumulated precipitation in spring $\left(\mathrm{P}_{\text {spring }}\right)$ for interannual variations in $\mathrm{SOS}$ based 
on redundancy analysis and identify temporal-spatial pattern of SOS responses to critical climate factors on the Tibetan Plateau. This is an important step toward understanding the mechanistic effects and underlying causes of climate change on vegetation phenology.

\section{Materials and Methods}

\subsection{Study Area}

The Tibetan Plateau lies at an average altitude of over $4000 \mathrm{~m}$ in southwest China (Figure 1), with a typical alpine climate environment and unique composition and distribution of alpine grassland, along with a low level of human interference. Across the entire plateau, the annual mean temperature varies from $-15{ }^{\circ} \mathrm{C}$ to $10{ }^{\circ} \mathrm{C}$, and the annual cumulative precipitation decreases from more than $1000 \mathrm{~mm}$ to $50 \mathrm{~mm}$. Recently, the Tibetan plateau experienced substantial climate change characterized by significant warming [9-12]. Meanwhile, numerous studies showed that vegetation was highly sensitive to climate changes on the Tibetan Plateau $[9,12,15,27]$. Hence, climate change and its increasingly pronounced effects on Tibetan Plateau grassland phenology are becoming an issue of global concern.

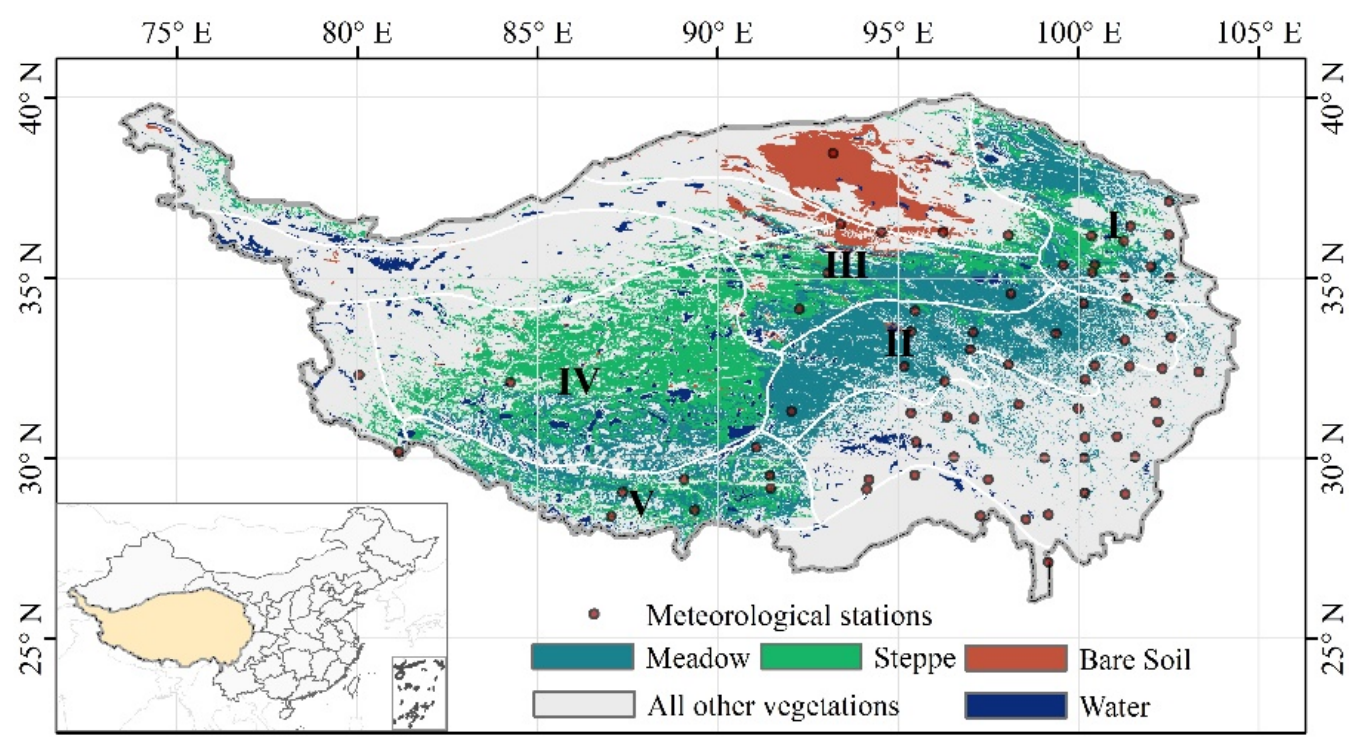

Figure 1. Location, ecoregions, and vegetation distribution for Tibetan Plateau. (I) Indicates Eastern Qinghai-Qilian montane steppe ecoregions; (II) indicates Golog-Nagqu high-cold shrub-meadow ecoregions; (III) indicates southern Qinghai high cold meadow steppe ecoregions; (IV) indicates Qiangtang high-cold steppe ecoregions; and (V) indicates Southern Xizang montane shrub-steppe ecoregions [31]. Pixels with annual maximum normalized difference vegetation index (NDVI) greater than 0.15 and mean NDVI of July to August larger than $1.35 \times$ NDVI during November to February are shown.

\subsection{Datasets}

During the past two decades, the monitoring of vegetation phenology at large-scale regional units was widely achieved using satellite remote sensing. In this study, we first produced an NDVI (normalized difference vegetation index) dataset by using MODIS (moderate resolution imaging spectroradiometer) surface reflectance products with a spatial resolution of $500 \mathrm{~m}$ and a compositional period of 8 days from 2000 to 2017 [32], obtained from the LPDAAC (land processes distributed active archive center, https:/ / lpdaacsvc. cr.usgs.gov/appeears/. Accessed 21 April 2021). To match the spatial resolution of the climatic factors, we then resampled these NDVI datasets to a resolution of $1 \mathrm{~km}$ and used them to determine vegetation SOS.

Information about the meadow and steppe distribution on the Plateau was obtained from the 1:1,000,000 vegetation map of China [33], created by the Chinese Academy of Sci- 
ences, using datasets from field observations, aerial photos, TM (landsat thematic mapper) and ETM (enhanced thematic mapper) satellite images [34,35]. Climate factors at meteorological stations, including the mean air temperature $\left({ }^{\circ} \mathrm{C}\right)$, accumulative precipitation $(\mathrm{mm})$ in spring (March-May), and the mean air temperature $\left({ }^{\circ} \mathrm{C}\right)$ in winter (December-February) were obtained from the China Meteorological Data Service Center. Based on the DEM (digital elevation model) data with $1 \mathrm{~km}$ spatial resolution produced by United States Geological Survey (USGS) and the 71 meteorological stations with complete records on the Tibetan Plateau (Figure 1), we calculated the spatial grid distribution of accumulated precipitation and mean temperature in spring using ANUSPLIN interpolation. Specifically, considering there were fewer than 2000 meteorological stations, we first employed the SPLNEA module to calculate the surface fitting parameters and their error covariance. Based on the latitude, longitude, and elevation information in a grid cell provided by DEM, the fitted climatic values and corresponding predicted standard error in the grid were then calculated by using the LAPGRD module [36-38].

\subsection{Preprocessing of NDVI Data}

Due to the inevitable impact of bare soils, sparsely vegetated grids, atmospheric contamination, etc., there were still many spurious changes in the NDVI time series [9,34,39]. Hence, to improve the quality of annual NDVI time series, the Savitzky-Golay filter for NDVI time series was conducted first. Additionally, we only selected pixels that met the following principles simultaneously to analyze the relative contributions of climate factors and their underlying combined effect on grassland spring phenology. First, the annual maximum NDVI must be greater than 0.15, and then the mean NDVI of July to August must be larger than $1.35 \times$ NDVI during November to February. The spatial distribution of valid pixels is displayed in Figure 1.

\subsection{Estimation of Grassland Spring Phenology}

In this section, the 18-year averaged NDVI value with a compositional period of 8 days was calculated from the entire data set during 2000-2017. Based on this long-term averaged NDVI time series data, subsequent analysis and calculation were conducted. Specifically, two different methods were employed to detect the grassland spring phenology on the Tibetan Plateau.

\subsubsection{Calculating the NDVI Thresholds Based on the Relative Rates of Changes}

Based on the long-term averaged NDVI time series data, we first calculated the relative rates of changes of NDVI (NDVI_rate) for each valid pixel (Equation (1)). The dynamic NDVI threshold for each pixel was defined based on the highest positive relative change rate; that is, the maximum NDVI_rate corresponding to NDVI is the dynamic NDVI threshold for detecting SOS (Figure 2).

$$
\text { NDVI_rate }(t)=[\operatorname{NDVI}(t+1)-\operatorname{NDVI}(t)] / \operatorname{NDVI}(t)
$$

where NDVI_rate( $\mathrm{t}$ ) is the relative rate of change in NDVI, $\mathrm{t}$ is the time at 8-day intervals, and NDVI $(t)$ is the averaged 8-day NDVI value at $t$ time. 


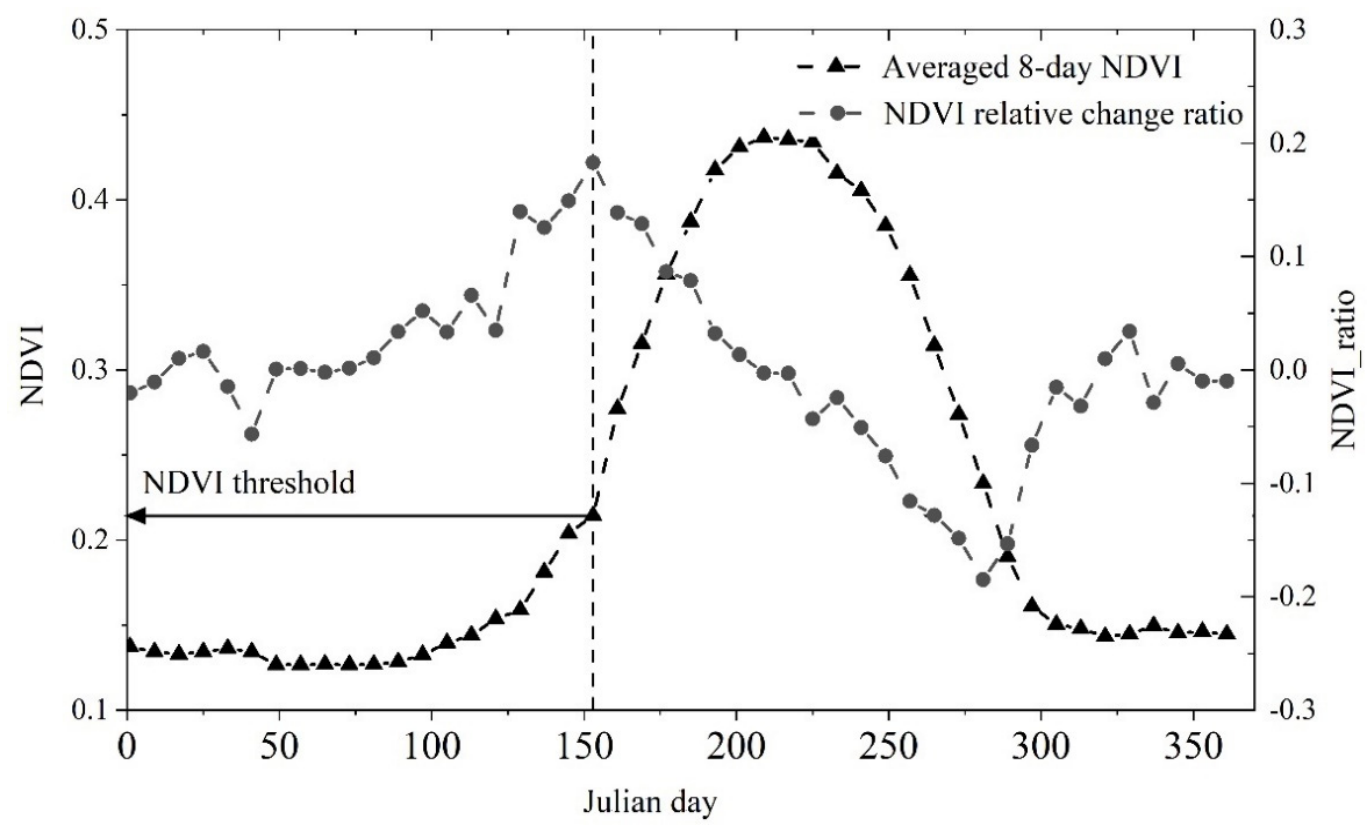

Figure 2. Schematic figures for calculating NDVI thresholds based on relative rates of change for NDVI time series. NDVI value of each point is mean value of grassland on Tibetan Plateau.

\subsubsection{Polyfit Method}

The polyfit method was initially applied to determine the vegetation spring phenology by Piao et al. [29]. Polyfit was widely shown to be one of the most efficient methods for the extraction of the vegetation phenology $[8,29]$. In general, the growing season of the grassland ranges from April to October in most areas of the Tibetan Plateau; that is, the NDVI value of grassland increased first, and then decreased with the increasing numbered day of the year during the growing season. Therefore, a 6-degree polynomial with a least-square analysis can be performed to reconstruct the daily NDVI time series from the original 8-day NDVI data during January to September. The polynomial function is shown in Equation (2):

$$
\operatorname{NDVI}(\mathrm{t})=\mathrm{a} 0+\mathrm{a} 1 \times \mathrm{t}+\mathrm{a} 2 \times \mathrm{t}^{2}+\mathrm{a} 3 \times \mathrm{t}^{3}+\mathrm{a} 4 \times \mathrm{t}^{4}+\mathrm{a} 5 \times \mathrm{t}^{5}+\mathrm{a} 6 \times \mathrm{t}^{6}
$$

where NDVI $(t)$ is the NDVI at $t$ time fitted by the polynomial equation. $t$ is the numbered day of the year. a0, a1, a2, a3, a4, a5, a6 are the fitted coefficient derived from least-square regression analysis. The multiple linear regression function in MATLAB R2019b was used to estimate these fitted coefficients.

\subsubsection{Harmonic Analysis of Time Series (HANTS) Method}

The HANTS method was also used to reconstruct the daily NDVI time series from the original 8-day NDVI data. HANTS is regarded as an improved algorithm of the fast Fourier transform (FFT), which was proved to be one of the most efficient methods for the reconstruction of NDVI time series and the extraction of vegetation phenology $[8,40,41]$. The points with lower values than the neighbors are filtered during HANTS processing, and they are then reconstructed following Equation (3):

$$
\operatorname{NDVI}(\mathrm{t})=\mathrm{a}_{0}+\sum_{\mathrm{i}=1}^{\mathrm{n}} \mathrm{a}_{\mathrm{i}} \cos \left(\omega_{\mathrm{i}} \mathrm{t}-\varphi_{\mathrm{i}}\right)
$$

where NDVI $(t)$ is the NDVI fitted by the HANTS model, $t$ is the numbered day of the year. $\mathrm{a}_{0}$ and $\mathrm{a}_{\mathrm{i}}$ are the fitted coefficient of the HANTS model. $\mathrm{n}$ is the frequency, which is set to 1 for the grassland on the Tibetan Plateau. $\varphi_{\mathrm{i}}$ is the phase of the NDVI time series. $\omega_{\mathrm{i}}$ is set to $2 \pi$ in our study because the grassland on the Tibetan Plateau has a unique seasonal cycle. 
Based on the NDVI threshold and the fitted NDVI time series, the grassland SOS was determined for each pixel and each year. Specifically, the numbered day of the year when the pixel's NDVI value was first larger than the calculated NDVI threshold during the growing season was regarded as the grassland SOS.

\subsection{Relationships between SOS and Climate}

Generally, it is difficult to quantitatively estimate the individual contributions of temperature and precipitation for the interannual variation in vegetation phenology because of the nonlinear impacts and underlying interactions of climate factors. In this research, the redundancy analysis (RDA) was utilized to calculate the independent contribution of $\mathrm{T}_{\text {winter }}, \mathrm{T}_{\text {spring }}$ and $\mathrm{P}_{\text {spring }}$ to interannual variations in SOS [42,43]. The RDA is regarded as a direct extension of multiple linear regression and principal component analysis based on canonical multivariate analyses. Based on this method, multiple response variables could be regressed on multiple explanatory variables, and the explanation proportion of each explanatory variable to response variables can be estimated and summarized [44-46]. This processing of RDA was demonstrated by Eigen analysis in the following equation:

$$
\left(S_{y x} S_{x x}^{-1} S_{y x}^{\prime}-\lambda_{k} I\right) u_{k}=0
$$

where $S_{y x}$ is the covariance matrix among response variables and explanatory variables, $S_{x x}^{-1}$ is the standardized explanatory variables' inverse covariance matrix, $\lambda_{k}$ represents the eigenvalue of the corresponding axis $k, I$ is unit matrix, and $u_{k}$ is normalized canonical eigenvectors.

In our study, a detrended correspondence analysis with the turnover units smaller than three was first conducted to confirm the suitability of an RDA. The adjusted coefficient of determination obtained from the Hierarchical Partitioning algorithm was regarded as the independent contribution of $\mathrm{T}_{\text {winter }}, \mathrm{T}_{\text {spring }}$ and $\mathrm{P}_{\text {spring }}$ to interannual variations in SOS (https:/ / github.com/laijiangshan/rdacca.hp/, Accessed 27 July 2020). Specifically, we first conducted RDA for each ecoregion and the entire plateau to estimate the contribution of each factor at the ecoregional scale. Furthermore, the RDA was conducted for each valid pixel to analyze spatial patterns of relative contribution of each factor and determine the dominant factor and the proportion of corresponding dominating factors. The Bonferroni test and Monte Carlo permutation methods (Permutations $=499$ ) were used to analyze the statistical significance $[44,46,47]$. In addition, to understand the spatial heterogeneity of the independent contribution of each factor, we performed linear regression in which the individual contribution of each climate factor was set to the dependent variable against the long-term average $\mathrm{P}_{\text {spring }}$ and $\mathrm{T}_{\text {spring }}$ across the Tibetan Plateau.

\section{Results}

\subsection{Interannual Variations in SOS}

Across the Tibetan Plateau, most pixels' SOS showed an advanced trend (a negative linear trend) during 2000-2017, despite the spatial heterogeneity of trends in SOS revealed by the two different methods (Figure 3). That is, the timing of first and mean spring life history events advanced in time due to climate change. The average SOS of both methods advanced over about $72.42 \%$ of all the study areas, and most pixels advanced between $0-0.50$ days per year ${ }^{-1}$ during the entire 18 -year period (Figure 3c). Spatially, both methods showed widespread advancing trends over the central and eastern Plateau, while a slight delayed trend in spring phenology was found in a few areas of the central and western Plateau. More specifically, $19.80 \%$ of pixels advanced significantly $(p<0.05)$, which were mainly located in the eastern ecoregions. While the pixels with delayed trend were discretely distributed across the midwestern region of the Plateau, only $2.25 \%$ of pixels were statistically significant $(p<0.05)$. These similar proportions and spatial patterns were also revealed by the two different methods, and the results revealed an advanced trend of SOS from Polyfit and HANTS at $74.26 \%$ of pixels (pixels with a significant advanced trend 
correspond to $24.58 \%, p<0.05$, Figure 3 a) and $71.81 \%$ of pixels $(22.03 \%$ with a significant advanced trend, $p<0.05$, Figure $3 b$ ), respectively.

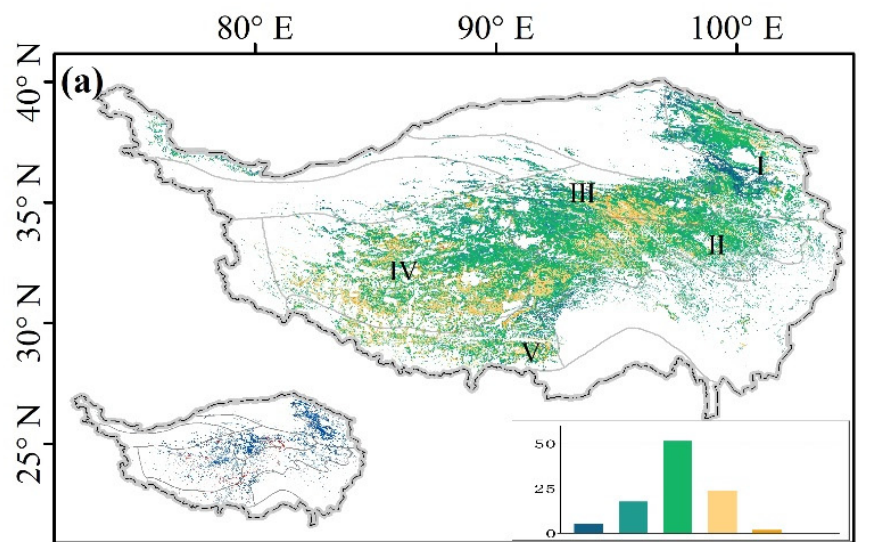

The linear trend of SOS (days year ${ }^{-1}$ )

\begin{tabular}{lllllll}
\hline$<-1$ & -1 & -0.5 & 0 & 0.5 & 1.0 & $>1.0$
\end{tabular}

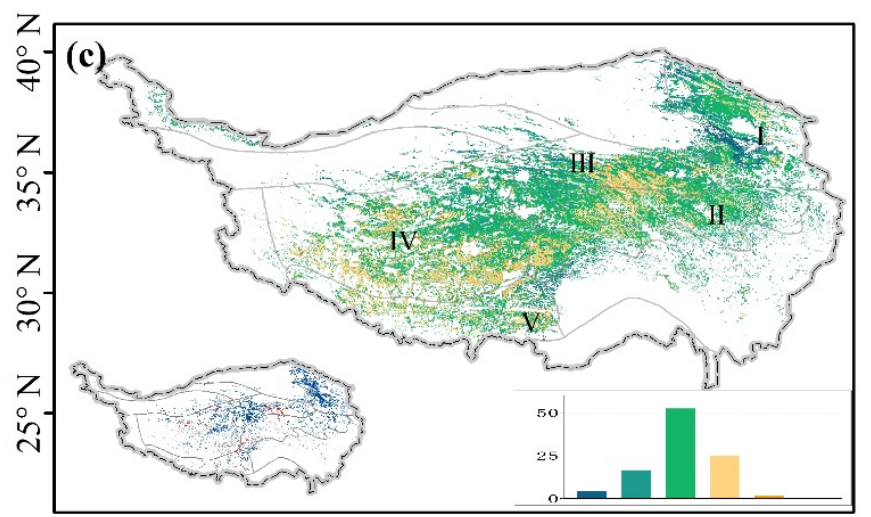

The linear trend of SOS (days year ${ }^{-1}$ )

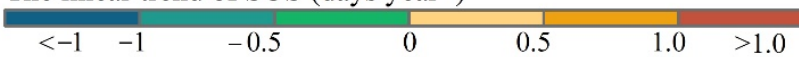

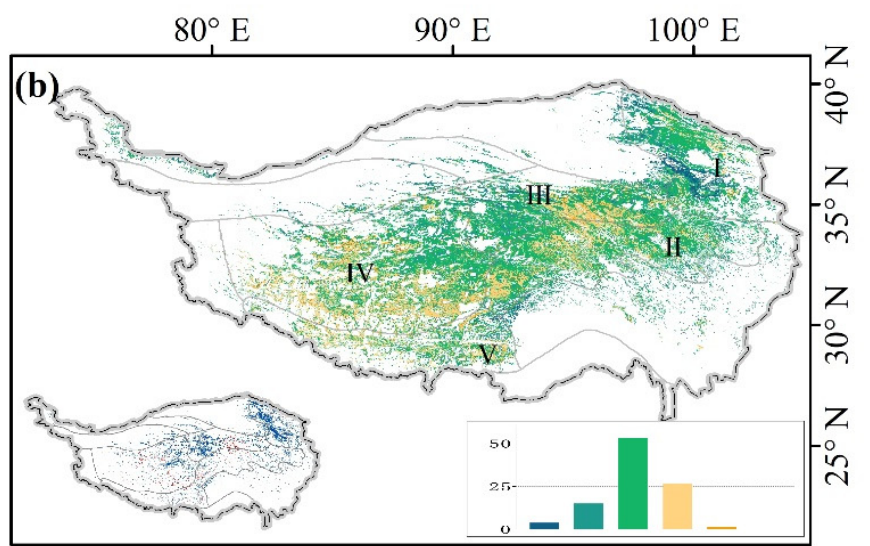

The linear trend of SOS (days year ${ }^{-1}$ )

$\begin{array}{lllllll}<-1 & -1 & -0.5 & 0 & 0.5 & 1.0 & >1.0\end{array}$

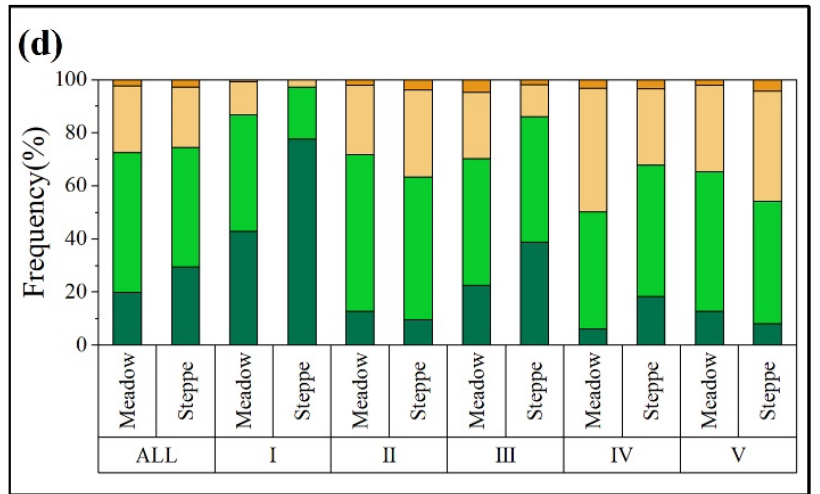

$\square$ SigD

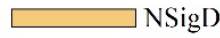

NSigA SigA

Figure 3. Spatial distribution and frequency statistics of linear trends of grassland spring phenology (SOS) from Polyfit (a); HANTS (b) and average of two methods (c) during 2000-2017 and frequency distribution of different trend types for steppe and meadow across different ecoregions (d). A negative value indicates an advance, and a positive value indicates a delay. Bottom-right and bottom-left insets in $(\mathbf{a}-\mathbf{c})$ show proportion of corresponding trends, indicated by map legend and spatial distribution of pixels with significantly negative (blue) and positive (red) trends $(p<0.05)$, respectively. SigD indicates significantly delayed SOS $(p<0.05)$. NSigD indicates delayed SOS but not significant $(p>0.05)$. NSigA indicates advanced SOS but not significant $(p>0.05)$. SigA indicates significantly advanced SOS $(p<0.05)$. All indicates entire plateau. I, II, III, IV, and V indicate different ecoregions following Figure 1.

With respect to meadows and steppe in different ecoregions, all methods agreed on an advanced trend (negative) over the entire study period but without consistent significance (Table 1). Specifically, the trends in the multimethod averaged SOS were $-0.30(p<0.01)$ and $-0.20(p<0.01)$ days per year ${ }^{-1}$ for steppe and meadow in the entire plateau, respectively. Regarding the two different models' results, the trend of SOS for meadow across the entire plateau estimated from Polyfit was $-0.21(p<0.01)$, while the result estimated from HANTS was slightly lower (Slope $=-0.19, p<0.01$ ). Regarding steppe across the entire plateau, a similar pattern can be found: the advanced trend of SOS from Polyfit and HANTS was $-0.32(p<0.01)$ and $-0.27(p<0.01)$, respectively. 
Table 1. Linear trends in multimethod averaged spring phenology (SOS) for steppe and meadow in different ecoregions from 2000-2017.

\begin{tabular}{lll}
\hline \multicolumn{1}{c}{ Ecoregions } & Meadow & Steppe \\
\hline ALL (Entire plateau) & $\mathbf{- 0 . 2 0 * *}$ & $\mathbf{- 0 . 3 0 * *}$ \\
I (Eastern Qinghai-Qilian montane steppe ecoregion) & $-\mathbf{0 . 3 0} * *$ & $-\mathbf{0 . 8 2} * *$ \\
II (Golog-Nagqu high-cold shrub-meadow ecoregion) & -0.15 & -0.07 \\
III (Southern Qinghai high-cold meadow steppe ecoregion) & -0.17 & $-\mathbf{0 . 3 7} * *$ \\
IV (Qiangtang high-cold steppe ecoregion) & -0.02 & -0.16 \\
V (Southern Xizang montane shrub-steppe ecoregion) & -0.11 & -0.11 \\
\hline Bold and symbols ** indicate significance levels at $p<0.05$. Trends with no asterisk are not significant $(p>0.10)$.
\end{tabular}

Concerning the different ecoregions, $42.88 \%$ of meadow and $77.53 \%$ of steppe showed a significant advanced trend $(p<0.05)$ (Figure 3d), with the mean linear trends of -0.30 $(p<0.01)$ and $-0.82(p<0.01)$ days per year ${ }^{-1}$ in the I ecoregion in the eastern Tibetan Plateau. Moreover, the SOS for steppe in the III ecoregion also significantly advanced by -0.37 days year ${ }^{-1}(p<0.01)$ according to the ensemble method, while no statistically significant trend for meadow in this ecoregion was observed at the $p>0.05$ level. No statistically significant trend in SOS for meadow or steppe was found in IV and V ecoregions, which resulted from the substantial spatial heterogeneity of the trends in SOS, with a widespread delayed trend in these ecoregions.

\subsection{Responses of SOS to Climate Factors}

Across the Plateau, the interannual variations in SOS for meadow were dominated by $\mathrm{T}_{\text {spring, }}$, with an individual contribution of $19.90 \%(p<0.05)$ and partial correlation coefficient (PCC) of $-0.48(p<0.05)$. By contrast, the steppe's SOS was more strongly affected by the interactions of precipitation and temperature, with an individual contribution of $\mathrm{P}_{\text {spring }}$ and $\mathrm{T}_{\text {spring }}$ of $15.90 \%(p<0.1)$ and $13.30 \%(p<0.1)$, respectively (Table 2$)$. Although higher PCC values were found between the SOS of steppe and $\mathrm{P}_{\text {spring }}$ and $\mathrm{T}_{\text {spring, }}$, with a PCC of -0.47 $(p<0.1)$ and $-0.43(p<0.1)$, respectively, the individual contribution of $\mathrm{P}_{\text {spring }}$ and $\mathrm{T}_{\text {spring }}$ was still lower.

Table 2. Responses of SOS to $\mathrm{T}_{\text {winter }}, \mathrm{T}_{\text {spring, }}$, and $\mathrm{P}_{\text {spring }}$ for steppe and meadow in different ecoregions.

\begin{tabular}{|c|c|c|c|c|c|c|c|}
\hline & & & Meadow & & & Steppe & \\
\hline & & $\mathbf{T}_{\text {winter }}$ & $\mathbf{T}_{\text {spring }}$ & $\mathbf{P}_{\text {spring }}$ & $\mathbf{T}_{\text {winter }}$ & $\mathbf{T}_{\text {spring }}$ & $\mathbf{P}_{\text {spring }}$ \\
\hline & ALL & -0.33 & $-0.48 * *$ & -0.10 & -0.08 & $-0.47 *$ & $-0.43 *$ \\
\hline & I & -0.33 & $-0.57 * *$ & -0.13 & -0.22 & -0.37 & $-0.41 *$ \\
\hline Partial correlation coefficient between & II & -0.25 & -0.35 & 0.24 & $-0.60 * *$ & -0.14 & -0.15 \\
\hline SOS and each factor & III & -0.31 & -0.10 & -0.12 & -0.38 & -0.29 & -0.39 \\
\hline & IV & 0.19 & -0.30 & $-0.58 * *$ & 0.04 & $-0.53 * *$ & $-0.61 * *$ \\
\hline & $\mathrm{V}$ & 0.28 & 0.07 & -0.13 & 0.15 & -0.06 & -0.37 \\
\hline & ALL & 6.13 & $19.90 * *$ & 0.00 & 0.00 & $13.30 *$ & $15.90 *$ \\
\hline & I & 2.13 & $24.16 * *$ & 1.08 & 0.00 & 5.52 & 14.16 * \\
\hline Individual contribution of each factor & II & 6.55 & $15.04 *$ & 3.22 & $31.32 * *$ & 2.09 & 0.00 \\
\hline from RDA (\%) & III & 10.8 & 0.00 & 0.00 & 11.4 * & 6.66 & 5.00 \\
\hline & IV & 0.00 & 1.82 & $18.47 * *$ & 0.00 & 12.78 * & $20.98 * *$ \\
\hline & $\mathrm{V}$ & 0.89 & 0.00 & 0.00 & 0.00 & 0.00 & 5.08 \\
\hline
\end{tabular}

Bold and symbols ${ }^{* *}$ and ${ }^{*}$ indicate significance levels at $p<0.05$ and at $p<0.1$, respectively. All indicates entire plateau. I, II, III, IV, and V indicate different ecoregions following Figure 1 . $\mathrm{T}_{\text {winter }}$ indicates mean temperature in winter; $\mathrm{T}_{\text {spring }}$ indicates mean temperature in spring. $\mathrm{P}_{\text {spring }}$ indicates accumulated precipitation in spring. Mean $\mathrm{T}_{\text {winter }}, \mathrm{T}_{\text {spring, }}$, and $\mathrm{P}_{\text {spring }}$ and SOS were first calculated for each ecoregion and entire plateau. RDA was then conducted at ecoregional scale.

Spatially, the individual contribution of $\mathrm{T}_{\text {winter }}, \mathrm{T}_{\text {spring }}$ and $\mathrm{P}_{\text {spring }}$ to interannual variations in SOS revealed a distinct east west disparity (Figure 4). The results showed that $\mathrm{P}_{\text {spring }}$ most strongly dominated vegetation SOS over $18.44 \%$ of pixels, which were mainly 
located in the IV ecoregion (Qiangtang high-cold steppe ecoregion) in the western region of the Plateau. However, $\mathrm{T}_{\text {spring }}$ dominated over $12.85 \%$, mainly located in the I ecoregion (eastern Qinghai-Qilian montane steppe ecoregion) in the eastern part of the Plateau. In addition, the statistical analysis showed that $\mathrm{T}_{\text {winter }}$ has the highest individual contribution in the central Plateau, with a proportion of $18.94 \%$ and $22.78 \%$ in the II (Golog-Nagqu high-cold shrub-meadow ecoregion) and III (southern Qinghai high-cold meadow steppe ecoregion) ecoregions in the central Plateau, respectively (Figure 4a).

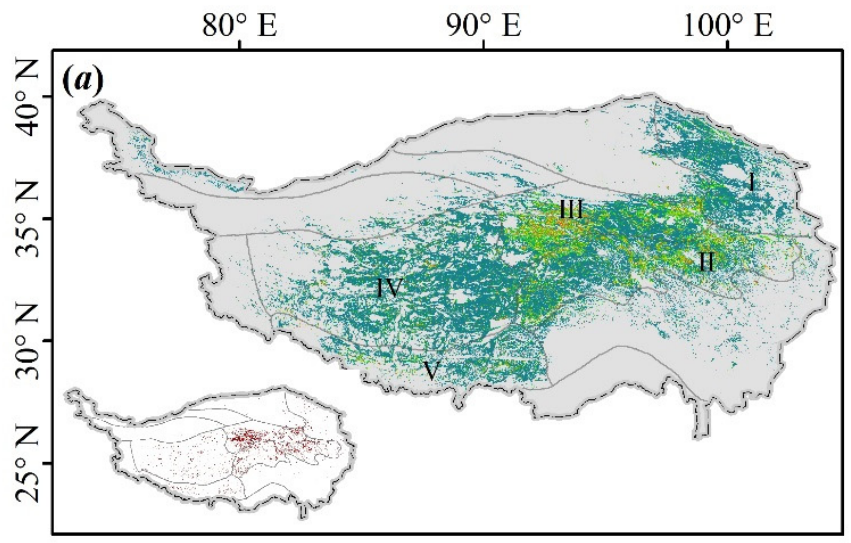

The explain power of mean temperature in winter $(\%)$

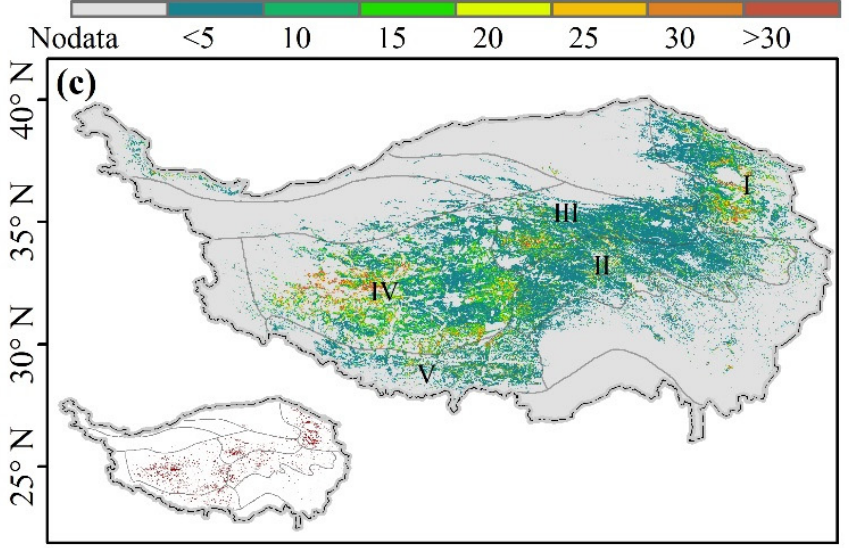

The explain power of accumulated precipitation in spring $(\%)$

\begin{tabular}{lllllllll}
\hline Nodata & $<5$ & 10 & 15 & 20 & 25 & 30 & $>30$
\end{tabular}

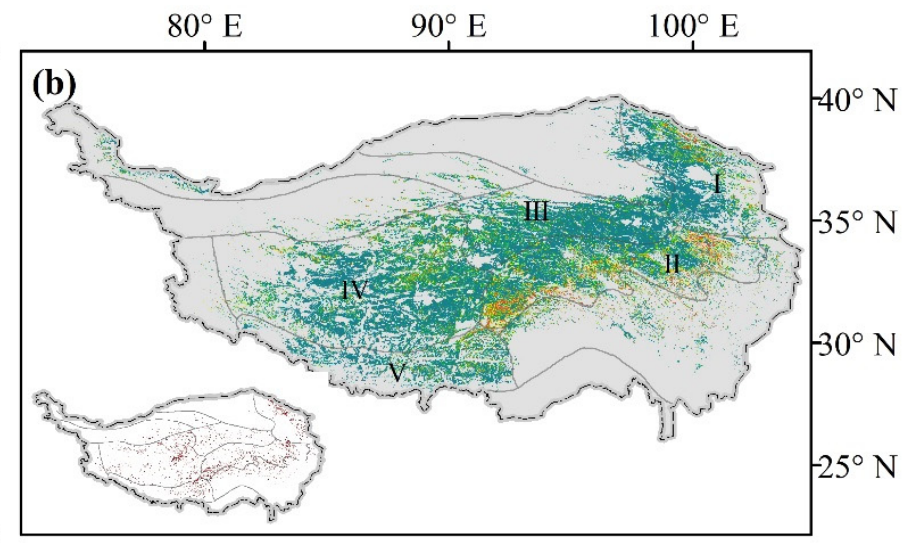

The explain power of mean temperature in spring (\%)

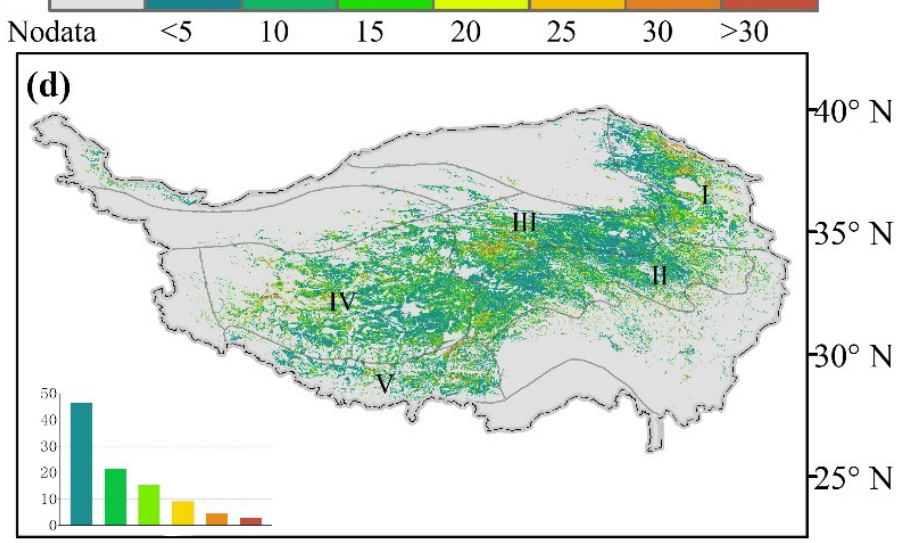

Accumulated explain power of three climate variables (\%)

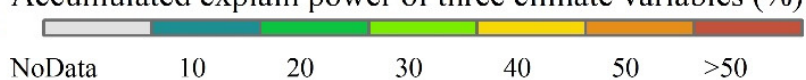

Figure 4. Spatial patterns of individual contribution of $\mathrm{T}_{\text {winter }}(\mathbf{a}), \mathrm{T}_{\text {spring }}(\mathbf{b})$, and $\mathrm{P}_{\text {spring }}$ (c) to interannual variation in SOS and cumulative contribution of all factors (d). Inset in (a-c) shows spatial distribution of pixels with significant trend $(p<0.05)$, and inset in $(\mathbf{d})$ shows proportion of corresponding accumulated contribution indicated by map legend. I, II, III, IV, and V indicate different ecoregions following Figure 1.

Across the Tibetan Plateau, the responses of SOS to the interactions of temperature and precipitation were more prominent for steppe and meadow in the different ecoregions (Table 2 and Figure 5). Across the I ecoregion, 26.62\% of the pixels for meadow were dominated by $\mathrm{T}_{\text {spring, }}$, with an individual contribution of $24.16 \%(p<0.05)$ and PCC of $-0.57(p<0.05)$. By contrast, the SOS of meadow in the IV ecoregion in the western part of the Plateau was dominated by $\mathrm{P}_{\text {spring, }}$, with an individual contribution of $18.47 \%$ $(p<0.05)$ and PCC of $-0.58(p<0.05)$. With respect to the steppe on the Tibetan Plateau, $27.72 \%$ of the pixels for steppe in the I ecoregion were dominated by $\mathrm{P}_{\text {spring. }}$. The individual contribution of $\mathrm{P}_{\text {spring }}$ to the interannual variations in SOS in this ecoregion was $14.16 \%$ $(p<0.1)$, and the PCC was $-0.41(p<0.1)$. While the interannual variations in SOS for steppe in the IV ecoregion in the western part of Tibetan Plateau were significantly 
affected by the underlying interactions of cumulative precipitation and mean temperature in spring. The individual contribution of $\mathrm{P}_{\text {spring }}$ and $\mathrm{T}_{\text {spring }}$ to the interannual variations in SOS was $20.98 \%(p<0.05)$ and $12.78 \%(p<0.1)$, respectively. The PCC between SOS and $\mathrm{P}_{\text {spring }}$ and $\mathrm{T}_{\text {spring }}$ was $-0.61(p<0.05)$ and $-0.53(p<0.05)$, respectively. These significant individual contribution and higher PCC indicated that interannual variations in SOS for steppe exhibited a close relationship with changes in climate conditions, illustrating the dependence of spring phenology on temperature and precipitation. In other words, an increase in preseason air temperature or cumulative precipitation would both correspond to a trend toward an earlier date of SOS. Our study also found that $\mathrm{T}_{\text {winter }}$ was the most significant factor for steppe in the II and III ecoregions in the central Plateau, with an individual contribution of $31.32 \%(p<0.05)$ and $11.40 \%(p<0.1)$, respectively.
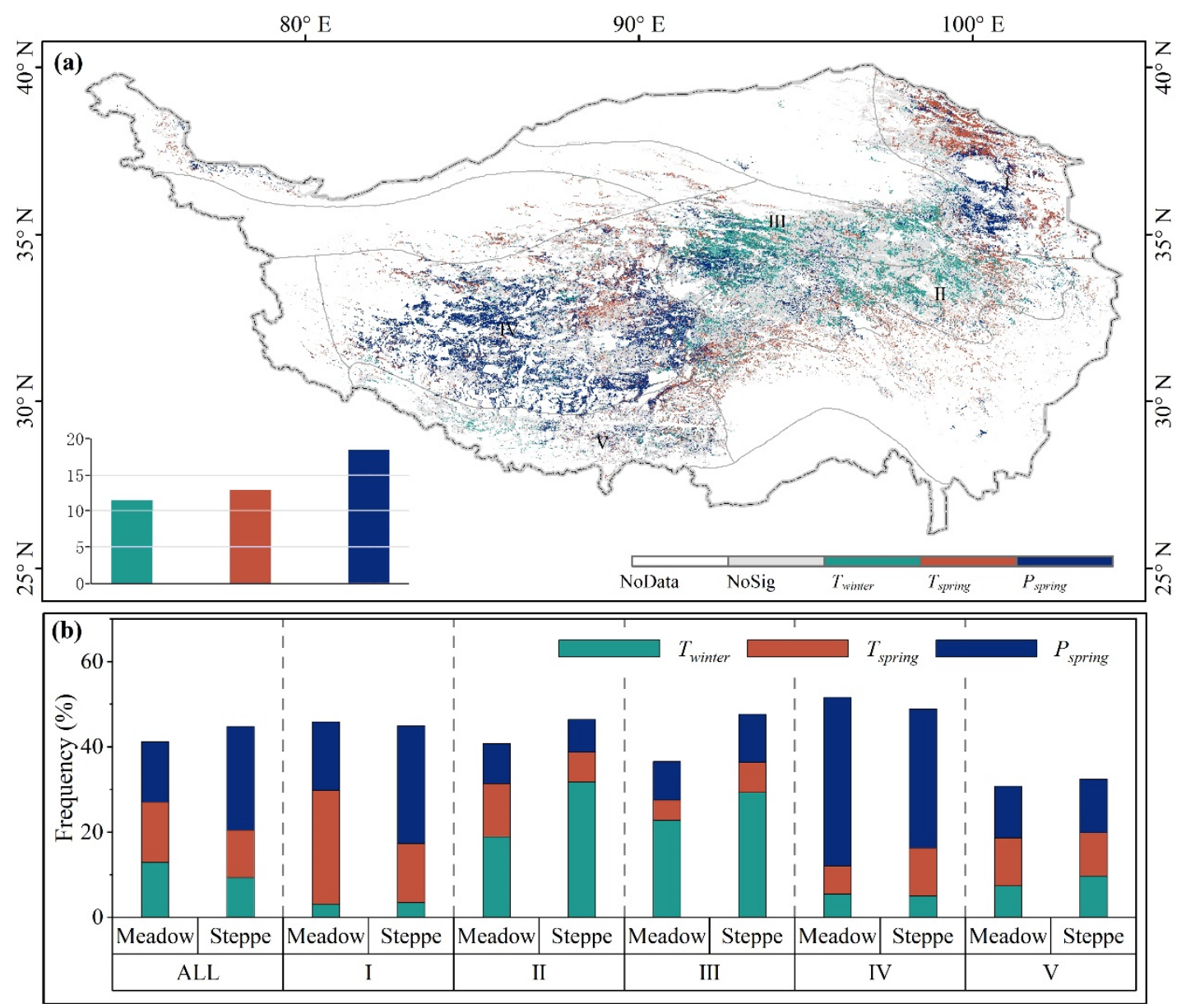

Figure 5. Spatial distribution of dominant drivers (a) and frequency of each dominating factor (b) in different ecoregions. Bottom-left inset in (a) shows proportion of corresponding dominating factors. Dominant drivers were determined by maximum individual contribution at $p<0.05$ level. NoSig indicates that none of these factors was significant $(p>0.05)$. All indicates entire plateau. I, II, III, IV, and $\mathrm{V}$ indicate different ecoregions following Figure 1.

\subsection{Relationship between Individual Contribution and Climate Gradient}

The spatial heterogeneities of responses of SOS to each factor can be fully explained by the long-term average precipitation gradient across the Tibetan Plateau (Figure 6). Spatially, the SOS of grassland in the Tibetan Plateau was more strongly affected by mean temperature in the wetter areas (I and II ecoregions), while it was dominated by the accumulated precipitation during spring in drier areas (IV ecoregion). Considering the values averaged from the pixels with significant individual contribution at $p<0.05$ level in different ecoregions in the Tibetan Plateau, a $10 \mathrm{~mm}$ increase in long-term average 
precipitation in spring responded to an increase in the individual contribution of $\mathrm{T}_{\text {spring }}$ of $1.70 \%(p<0.05)$, while it caused a decrease in an individual contribution of $\mathrm{P}_{\text {spring }}$ of $-0.70 \%(p<0.1)$ (Figure 6a). In contrast, among different ecoregions on the Tibetan Plateau, this pattern linking the relative contribution of each climate factor to long-term average mean temperature in spring was not found in our study (Figure 6b).
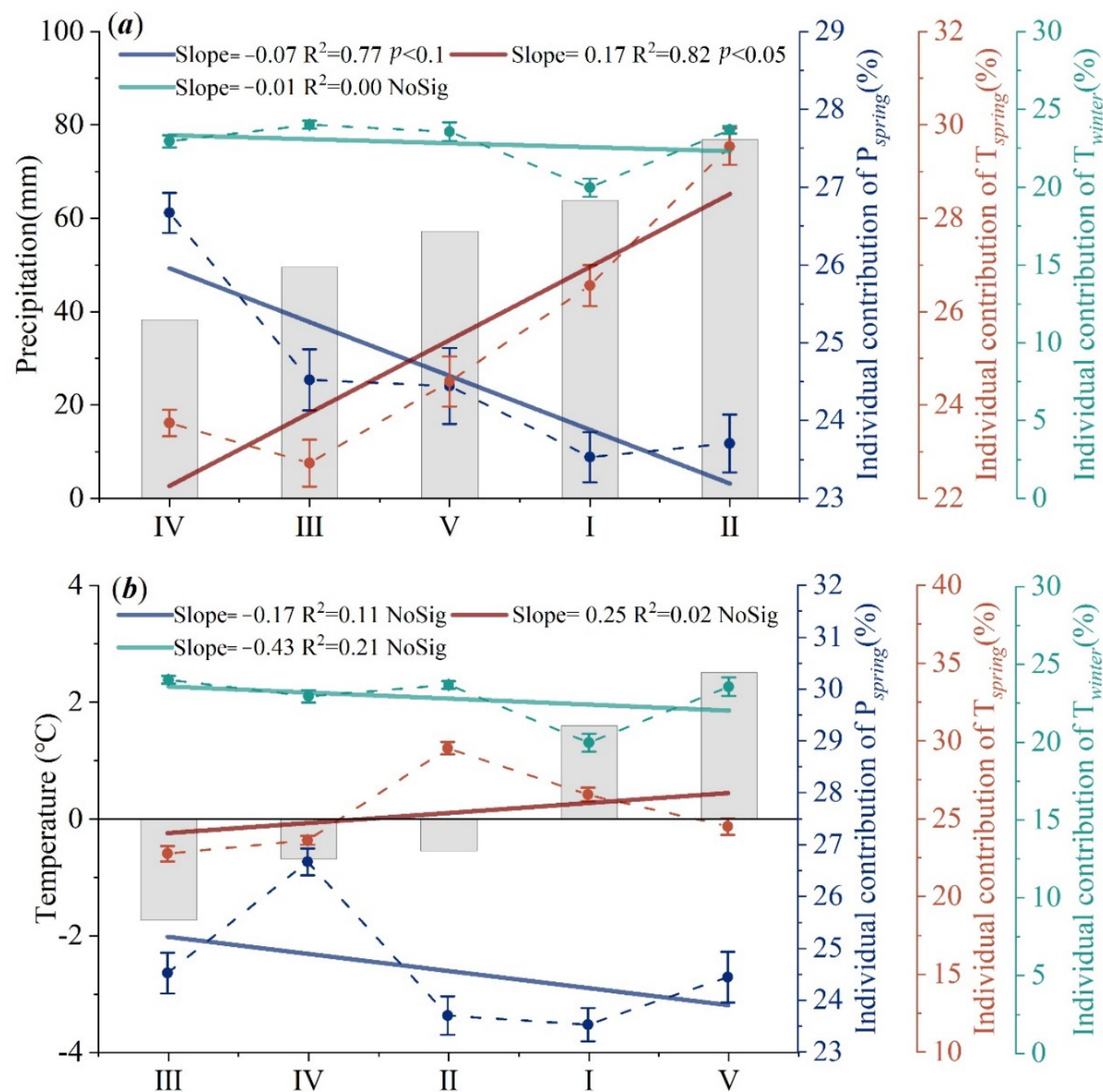

Figure 6. Variations in individual contribution of each climate factor for grassland spring phenology to long-term average cumulative precipitation (a) and mean temperature (b) in spring in different ecoregions across Tibetan Plateau. Bars indicate mean long-term average precipitation or temperature in spring for each ecoregion. Point and dashed curves represent averaged value of pixels with significant individual contribution at $p<0.05$ level for each ecoregion listed in right $y$-axis labels. Solid line represents linear regression of individual contribution of each climate factor to long-term average precipitation or temperature. $p$ value denotes significance. NoSig indicates that slope is not significant at $p \geq 0.05$ level. I, II, III, IV, and V indicate different ecoregions following Figure 1 .

Furthermore, this similar pattern of the impacts of long-term average cumulative precipitation on the contribution of each climate factor to the SOS among the different vegetation types was found (Figure 7). Specifically, a $10 \mathrm{~mm}$ increase in long-term average precipitation in spring resulted in an increase in the individual contribution of $\mathrm{T}_{\text {spring }}$ of $2.0 \%$ $(p<0.05)$ to the SOS of meadow, while it caused a decrease in the individual contribution of $\mathrm{P}_{\text {spring }}$ of $-0.30 \%(p<0.1)$ (Figure $\left.7 \mathrm{a}\right)$. Regarding steppe across the different ecoregions of the Tibetan plateau, these similar spatial variations were also found, with the sensitivity 
of individual contribution of $\mathrm{T}_{\text {spring }}$ and $\mathrm{P}_{\text {spring }}$ to the long-term average precipitation in spring of $0.07 \% \mathrm{~mm}^{-1}$ and $-0.14 \% \mathrm{~mm}^{-1}$, respectively (Figure $7 \mathrm{c}$ ).
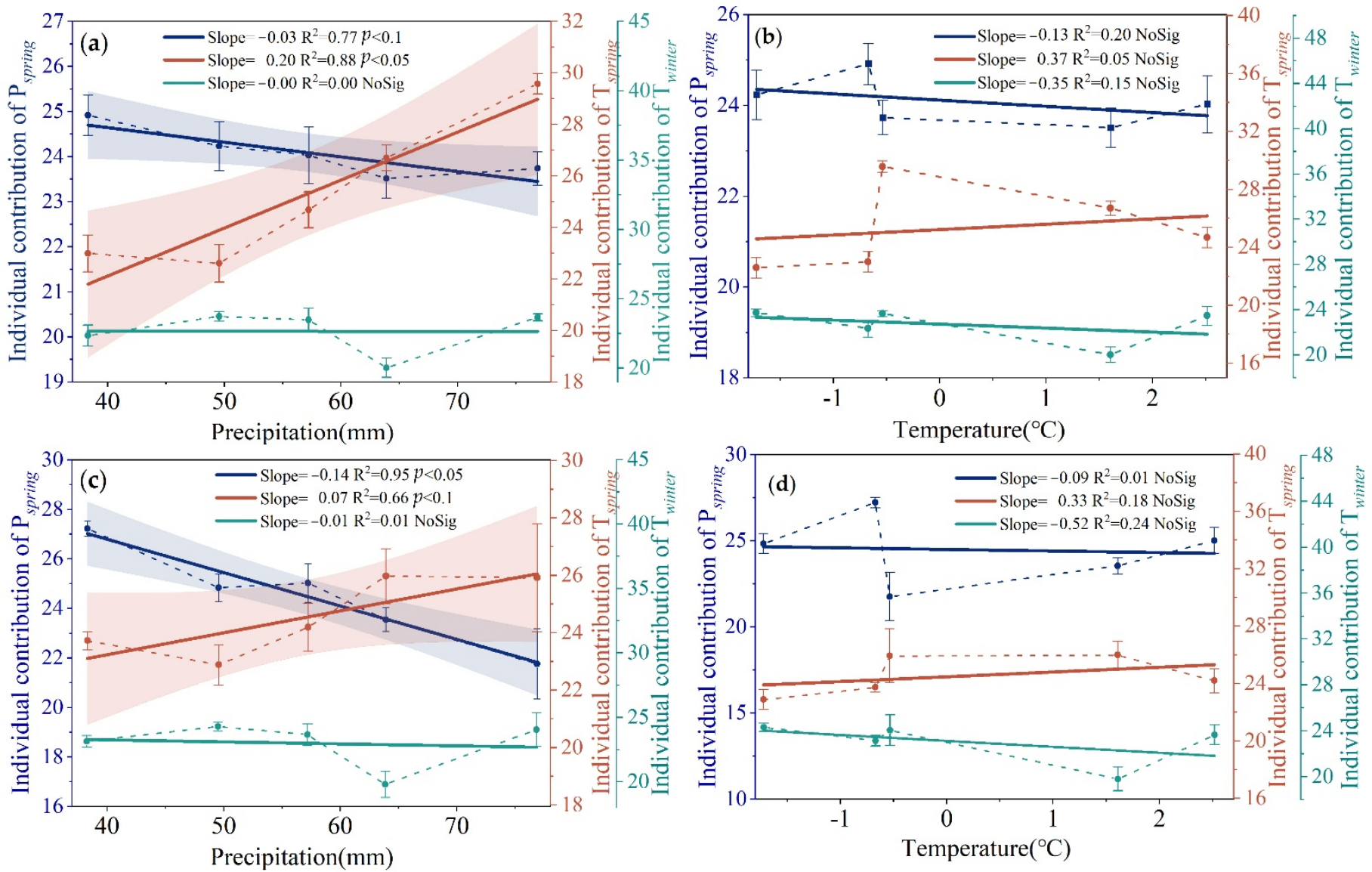

Figure 7. Variations in individual contribution of each climate factors for meadow $(\mathbf{a}, \mathbf{b})$ and steppe $(\mathbf{c}, \mathbf{d})$ to long-term average cumulative precipitation and mean temperature in spring in different ecoregions across Tibetan Plateau. Each point shows averaged values of pixels with significant individual contribution at $p<0.05$ level for meadow and steppe in different ecoregion. Error bar is SEM (standard error of mean). Line represents linear regression, and shaded area represents $95 \%$ confidence interval. $p$ value denotes significance. NoSig indicates that slope is not significant $(p \geq 0.05)$.

\section{Discussion}

\subsection{Interacting Effects of Temperature and Precipitation on Spring Phenology}

Variability, particularly variability in temperature and precipitation, unequivocally affected the vegetation phenology on the Tibetan Plateau $[5,9,12,15,27,28]$. However, the relative contribution of each factor and the underlying combined effect on vegetation phenology received much less attention. In this study, we found that the individual contribution of temperature and precipitation to spring phenology was lower, despite the higher correlation coefficient consistently shown by most previous studies. More importantly, individual contribution of temperature and precipitation to interannual variations in SOS revealed a distinct east west disparity across the Tibetan Plateau, which can be fully explained by long-term average precipitation gradient over the entire study period. This spatial pattern of the quantitative contribution of temperature and precipitation to interannual variations in spring phenology further confirmed the stronger interactions of precipitation and temperature and indicated underlying mechanisms of the responses of ecological functions of vegetation to climate change. 
With increasing temperature and precipitation [28,48], all methods in our study agreed on an advanced trend in SOS for meadow and steppe on the Tibetan Plateau during 2000-2017 despite the spatial heterogeneity, with an advanced SOS across most of the Plateau and a discretely distributed and delayed SOS in the midwestern region of the Tibetan Plateau. These complex trends in grassland spring phenology are generally supported by recent studies [28,30,49-51]. Most previous studies consistently showed that the increasing spring temperature was the major dominant driver of SOS advances [11,15,17,27,28,52]. However, the individual contribution of temperature and precipitation was lower, despite a higher correlation coefficient, which implied that these factors interact to affect the SOS across the Tibetan Plateau. The contributions of temperature and precipitation to the grassland spring phenology varied across space on the Tibetan Plateau, and these spatial heterogeneities can be mainly explained by the spatial gradient of long-term average precipitation over 2000-2017.

For meadow, the interannual variations in SOS were dominated by $\mathrm{T}_{\text {spring }}$ in the eastern I ecoregion with relatively mild climate. In these wetter areas, the soil moisture constraints were released. Without limitation of water resources, vegetation tended to maximize the thermal benefit and showed higher sensitivity to temperature than to precipitation $[12,28,53]$. In other words, better thermal-hydraulic conditions would accelerate the rates of chemical reactions because of the effect on Rubisco enzymatic activity and then speed up development processes in photosynthetic organisms [54,55]. Consequently, the individual contribution of temperature to SOS would be significant and largest, that is, the increasing preseason temperature would significantly stimulate plant growth and advance the SOS under this better thermal-hydraulic conditions. Similarly, Shen et al. [12] showed that the sensitivity of SOS to temperature was negative and significant in eastern and northeastern part of the Plateau, and Piao et al. [28] showed that the SOS could advance by an extra 4.5 days with an increase in spring temperature of $1^{\circ} \mathrm{C}$. In contrast, the interannual variations in SOS were strongly negatively correlated with $\mathrm{P}_{\text {spring }}$ in the western IV ecoregion with less precipitation. In those relatively dry ecoregions with spring precipitation of less than $100 \mathrm{~mm}$ [50], vegetation growth initiation after winters with low rainfall would be limited by water availability [56]. Limited water potential would inhibit plant growth and photosynthesis activities, increase the risk of chlorophyll degradation and plant mortality [57], and consequently delay the SOS. In addition, the soil moisture would be suboptimal because of the high evapotranspiration caused by increasing temperature [58]. Hence, the preseason precipitation would determine the water availability, and revealed a high individual contribution to the interannual variation in SOS.

Previous studies showed that meadow and steppe responded differently to climate change $[50,53,59]$. The different habitat conditions were primarily responsible for these various responsive characteristics. The steppe adapted to the long period of colder and drier weather with a shorter growth cycle. Thus, the steppe's ecological functions showed increased sensitivity to climate change [39,40,60-63]. Moreover, although the warming accelerates plant growth, it can also cause the decline of soil moisture, and then increase the sensitivity of vegetation phenology to precipitation $[5,27,53]$, which indicated that warming and precipitation would additionally interact to affect plant spring phenology in the drier area. Hence, changes and interaction between temperature and precipitation would affect the SOS for steppe significantly. Nonetheless, the long-term average precipitation gradient also dominated the spatial disparity of the individual contribution of precipitation and temperature; that is, the vegetation SOS would be less sensitive to temperature changes due to the lower long-term average precipitation, while the relative contribution of preseason precipitation would increase. These dynamic response patterns can be well explained by the vegetation adaptation strategy, which would maximize the benefit from the limiting climate factors and reduce the risk imposed by other factors [12].

Generally, precipitation and temperature were considered as two main regulators of vegetation activity on the Tibetan Plateau [24]. Their underlying combined effect on vegetation phenology suggested a vegetation adaptation strategy that achieves a balance 
between maximizing benefit and minimizing risk; that is, the vegetation would make the most of limiting climate factors and reduce the risks from other factors [12]. In the northeastern Tibetan Plateau, the vegetation spring phenology was strongly advanced by increasing temperature and slightly advanced by precipitation. The plant photosynthetic rate would be directly accelerated due to the effect of Rubisco enzymatic activity in these better thermal-hydraulic conditions [54]. In contrast, in the drier area, the higher spring temperature would cause the decline of soil moisture, and then increase the sensitivity of vegetation phenology to precipitation $[5,27,53]$, which indicated that warming and precipitation would additionally interact to affect plant spring phenology. Alternatively, the higher individual contribution of preseason precipitation to SOS in more arid areas indicated that plant would intensify spring drought because bulk canopy water needs to be increased with an advanced SOS under future climate warming. Overall, our analysis highlighted stronger interactions between warming and precipitation and quantified the relative contribution of each factor, which would benefit to gain an accurate mechanism and a better understanding of terrestrial ecosystem processes and their responses to future climate change.

\subsection{Uncertainties and Further Studies}

To account for the potential interactions and the individual contribution of each factor, we employed two different methods to detect SOS and conducted redundancy analysis. Although a similar spatial pattern of the SOS trend was revealed by these two methods, distinct values in the interannual variations still existed. The proportion of delayed trend of SOS from Polyfit was $25.74 \%$ (Figure 3a), which was slightly less than that from HANTS, which was $28.19 \%$ (Figure $3 \mathrm{~b}$ ). This distinction maybe caused by the spurious oscillations of the NDVI time series conducted in the HANTS and Polyfit methods $[8,64-67]$. Therefore, the results need to be further tested with more models to characterize more exact interannual variation in the SOS. In addition, previous studies showed that many other factors would also affect the vegetation phenology, for example, large diurnal temperature range [14,17,68,69], soil moisture [24,70-72], and some vegetation functions [73-75]. In addition, some studies also showed that the photoperiod could coregulate the vegetation spring phenology through its interaction with temperature or its influence on the stomata aperture and photosynthetic active radiation [22,23,56]. However, Fan et al. [76] showed that sunshine duration in the mountain plateau zone displayed an insignificantly negative trend $(p>0.05)$ at the rates of $-0.001 \mathrm{~h}_{\text {year }}{ }^{-1}$ during $1986-2015$. Thus, the photoperiod was roughly assumed to be a valid constant without the effect of cloudiness during the study period. Our study also found that $\mathrm{T}_{\text {winter }}$ was the most significant factor for the interannual variation of the steppe in the central Plateau, which could be attributed to warminginduced changes in soil moisture. Moreover, the vegetation would require adequate chilling conditions (vernalization) during endodormancy; therefore, grassland phenology is expected to be sensitive to winter warming $[13,21]$. Clearly, further analysis with more factors should be conducted to estimate more robust contribution of each factor, and then support these inferences and their role in the control over phenology. Nevertheless, our present work highlighted a stronger interaction between warming and precipitation, quantified the relative contribution of each factor, and identified temporal-spatial aspects of grassland SOS responses to critical climate factors on the Tibetan Plateau, which would provide a helpful reference and establish a better understanding for further studies on climate plant interactions.

\section{Conclusions}

This study quantified the individual contribution of warming and precipitation for the interannual variations in start of growing season (SOS) in the world's largest cold and arid/semiarid regions. Our results further confirmed the strong impacts of preseason precipitation on satellite-derived estimates of spring phenology of grassland across the Tibetan Plateau. First, the relative contribution of the accumulated precipitation in spring 
to interannual variations in SOS was higher in more arid than wetter areas. Alternatively, $\mathrm{P}_{\text {spring }}$ (the accumulated precipitation in spring) strongly dominated vegetation SOS over most pixels located in the western part of the Plateau. Second, although the responses of SOS to each factor were complex and fragmented across the Tibetan Plateau, these spatial heterogeneities can be mainly explained by the long-term average precipitation during spring. Specifically, the increase in long-term average precipitation during spring resulted in an increase in the individual contribution of $\mathrm{T}_{\text {spring }}$ to the SOS of grassland, while the individual contribution of the accumulated precipitation in spring would increase with the decrease in long-term average precipitation during spring. Alternatively, climate warming would have less impact on SOS than precipitation, which would lead to complex responses to climates change in these arid or semiarid regions. In addition, temperature in winter made a larger contribution, which would change soil moisture and strongly affect the SOS in the central Plateau. For the Tibetan plateau dominated by the arid/semiarid climate, considering the interactions of preseason temperature and precipitation and their stronger and more complex effect on SOS, vegetation would experience greater SOS advancement, with substantial warming in relatively wetter regions than in drier areas. Instead, substantial warming would slightly advance vegetation SOS and might delay SOS in the arid/semiarid regions because of the increase in evapotranspiration. Thus, the combined impacts and the quantitative contribution of warming and precipitation on SOS should be considered, while assessing the responses of vegetation to climates change rather than the unitary effect of one or more factors directly.

Author Contributions: Conceptualization, Y.W. and M.C.; methodology, software, and formal analysis, M.C.; data curation and validation, J.Z. and Y.P.; writing-original draft preparation, M.C.; writing-review and editing, Y.W. All authors have read and agreed to the published version of the manuscript.

Funding: This research was funded by National Natural Science Foundation of China (41807173, 41901233); National Science-Technology Support Plan Project, China (41501190); the MOE Project of Humanities and Social Sciences (19YJC630127) and the Natural Science Foundation of Zhejiang Province (LY20D010007, LQ18D010005).

Institutional Review Board Statement: Not applicable.

Informed Consent Statement: Not applicable.

Data Availability Statement: Not applicable.

Acknowledgments: We thank the Land Processes Distributed Active Archive Center for providing MODIS satellite data. We also thank the China Meteorological Data Service Center for providing meteorological data. We would like to thank Jiangshan Lai for providing the R package of rdacca.hp: Hierarchical Partitioning for Canonical Analysis. We thank the editors and the reviewers for their valuable suggestions which improved this paper.

Conflicts of Interest: The authors declare no conflict of interest.

\section{References}

1. Walther, G.R.; Post, E.; Convey, P.; Menzel, A.; Parmesan, C.; Beebee, T.; Fromentin, J.M.; Hoegh-Guldberg, O.; Bairlein, F. Ecological responses to recent climate change. Nature 2002, 416, 389-395. [CrossRef] [PubMed]

2. Chen, L.; Hänninen, H.; Rossi, S.; Smith, N.G.; Pau, S.; Liu, Z.; Feng, G.; Gao, J.; Liu, J. Leaf senescence exhibits stronger climatic responses during warm than during cold autumns. Nat. Clim. Chang. 2020, 10, 777-780. [CrossRef]

3. Hansen, G.; Cramer, W. Global distribution of observed climate change impacts. Nat. Clim. Chang. 2015, 5, 182-185. [CrossRef]

4. Franklin, J.; Serra-Diaz, J.M.; Syphard, A.D.; Regan, H.M. Global change and terrestrial plant community dynamics. Proc. Natl. Acad. Sci. USA 2016, 113, 3725-3734. [CrossRef] [PubMed]

5. Ganjurjav, H.; Gornish, E.S.; Hu, G.Z.; Schwartz, M.W.; Wan, Y.; Li, Y.; Gao, Q. Warming and precipitation addition interact to affect plant spring phenology in alpine meadows on the central Qinghai-Tibetan Plateau. Agric. For. Meteorol. 2020, $287,107943$. [CrossRef]

6. Wang, H.; Liu, H.; Cao, G.; Ma, Z.; Li, Y.; Zhang, F.; Zhao, X.; Zhao, X.; Jiang, L.; Sanders, N.J.; et al. Alpine grassland plants grow earlier and faster but biomass remains unchanged over 35 years of climate change. Ecol. Lett. 2020, 23, 701-710. [CrossRef] 
7. Piao, S.; Liu, Q.; Chen, A.; Janssens, I.A.; Fu, Y.; Dai, J.; Liu, L.; Lian, X.; Shen, M.; Zhu, X. Plant phenology and global climate change: Current progresses and challenges. Glob. Chang. Biol. 2019, 25, 1922-1940. [CrossRef]

8. Zeng, L.; Wardlow, B.D.; Xiang, D.; Hu, S.; Li, D. A review of vegetation phenological metrics extraction using time-series, multispectral satellite data. Remote Sens. Environ. 2020, 237, 111511. [CrossRef]

9. Shen, M.; Tang, Y.; Chen, J.; Zhu, X.; Zheng, Y. Influences of temperature and precipitation before the growing season on spring phenology in grasslands of the central and eastern Qinghai-Tibetan Plateau. Agric. For. Meteorol. 2011, 151, 1711-1722. [CrossRef]

10. Zheng, Z.; Zhu, W.; Chen, G.; Jiang, N.; Fan, D.; Zhang, D. Continuous but diverse advancement of spring-summer phenology in response to climate warming across the Qinghai-Tibetan Plateau. Agric. For. Meteorol. 2016, 194-202. [CrossRef]

11. Chen, H.; Zhu, Q.; Wu, N.; Wang, Y.; Peng, C. Delayed spring phenology on the Tibetan Plateau may also be attributable to other factors than winter and spring warming. Proc. Natl. Acad. Sci. USA 2011, 108, E93. [CrossRef] [PubMed]

12. Shen, M.; Piao, S.; Cong, N.; Zhang, G.; Jassens, I.A. Precipitation impacts on vegetation spring phenology on the Tibetan Plateau. Glob. Chang. Biol. 2015, 21, 3647-3656. [CrossRef] [PubMed]

13. Yu, H.; Luedeling, E.; Xu, J. Winter and spring warming result in delayed spring phenology on the Tibetan Plateau. Proc. Natl. Acad. Sci. USA 2010, 107, 22151-22156. [CrossRef] [PubMed]

14. Peng, S.; Piao, S.; Ciais, P.; Myneni, R.; Chen, A.; Chevallier, F.; Dolman, H.; Janssens, I.; Penuelas, J.; Zhang, G.; et al. Asymmetric effects of daytime and night-time warming on Northern Hemisphere vegetation. Nature 2013, 501, 88-92. [CrossRef] [PubMed]

15. Shen, M.; Piao, S.; Chen, X.; An, S.; Fu, Y.; Wang, S.; Cong, N.; Janssens, I. Strong impacts of daily minimum temperature on the green-up date and summer greenness of the Tibetan Plateau. Glob. Chang. Biol. 2016, 22, 3057-3066. [CrossRef] [PubMed]

16. Fu, Y.; Piao, S.; Zhao, H.; Jeong, S.J.; Wang, X.H.; Vitasse, Y.; Ciais, P.; Janssens, I. Unexpected role of winter precipitation in determining heat requirement for spring vegetation green-up at northern middle and high latitude. Glob. Chang. Biol. 2014, 20, 3743-3755. [CrossRef] [PubMed]

17. Huang, Y.; Jiang, N.; Shen, M.; Guo, L. Effect of preseason diurnal temperature range on the start of vegetation growing season in the Northern Hemisphere. Ecol. Indic. 2020, 112, 106-161. [CrossRef]

18. Lucht, W.; Prentice, I.C.; Myneni, R.B.; Sitch, S.; Friedlingstein, P.; Cramer, W.; Bousquet, P.; Buermann, W.; Smith, B. Climatic Control of the High-Latitude Vegetation Greening Trend and Pinatubo Effect. Science 2002, 296, 1687. [CrossRef]

19. Xu, L.; Myneni, R.B.; Chapin Iii, F.S.; Callaghan, T.V.; Pinzon, J.E.; Tucker, C.J.; Zhu, Z.; Bi, J.; Ciais, P.; Tømmervik, H.; et al. Temperature and vegetation seasonality diminishment over northern lands. Nat. Clim. Chang. 2013, 3, 581-586. [CrossRef]

20. Jeong, S.J.; Ho, C.H.; Gim, H.J.; Brown, M. Phenology shifts at start vs. end of growing season in temperate vegetation over the Northern Hemisphere for the period 1982-2008. Glob. Chang. Biol. 2011, 17, 2385-2399. [CrossRef]

21. Suonan, J.; Classen, A.T.; Zhang, Z.; He, J. Asymmetric winter warming advanced plant phenology to a greater extent than symmetric warming in an alpine meadow. Funct. Ecol. 2017, 31, 2147-2156. [CrossRef]

22. Way, D.A.; Montgomery, R.A. Photoperiod constraints on tree phenology, performance and migration in a warming world. Plant Cell Environ. 2015, 38, 1725-1736. [CrossRef] [PubMed]

23. Flynn, D.F.B.; Wolkovich, E.M. Temperature and photoperiod drive spring phenology across all species in a temperate forest community. New Phytol. 2018, 219, 1353-1362. [CrossRef] [PubMed]

24. Piao, S.; Wang, X.; Park, T.; Chen, C.; Lian, X.; He, Y.; Bjerke, J.W.; Chen, A.; Ciais, P.; Tømmervik, H.; et al. Characteristics, drivers and feedbacks of global greening. Nat. Rev. Earth Environ. 2020, 1, 14-27. [CrossRef]

25. Dai, J.; Wang, H.; Ge, Q. Multiple phenological responses to climate change among 42 plant species in Xi'an, China. Int. J. Biometeorol. 2013, 57, 749-758. [CrossRef]

26. Liu, H.; Tian, F.; Hu, H.C.; Hu, H.P.; Sivapalan, M. Soil moisture controls on patterns of grass green-up in Inner Mongolia: An index based approach. Hydrol. Earth Syst. Sci. 2013, 17, 805-815. [CrossRef]

27. Cong, N.; Wang, T.; Nan, H.; Ma, Y.; Wang, X.; Myneni, R.B.; Piao, S. Changes in satellite-derived spring vegetation green-up date and its linkage to climate in China from 1982 to 2010: A multimethod analysis. Glob. Chang. Biol. 2013, 19, 881-891. [CrossRef]

28. Piao, S.; Cui, M.; Chen, A.; Wang, X.; Ciais, P.; Liu, J.; Tang, Y. Altitude and temperature dependence of change in the spring vegetation green-up date from 1982 to 2006 in the Qinghai-Xizang Plateau. Agric. For. Meteorol. 2011, 151, 1599-1608. [CrossRef]

29. Piao, S.L.; Fang, J.J.Y.; Zhou, L.M.; Ciais, P.; Zhu, B.Y. Variations in Satellite-Derived Phenology in China's Temperate Vegetation. Glob. Chang. Biol. 2006, 12, 672-685. [CrossRef]

30. Shen, M.; Zhangf, G.; Cong, N.; Wang, S.; Kong, W.; Piao, S. Increasing altitudinal gradient of spring vegetation phenology during the last decade on the Qinghai-Tibetan Plateau. Agric. For. Meteorol. 2014, 189, 71-80. [CrossRef]

31. Zheng, D. The system of physico-geographical regions of the Qinghai-Xizang (Tibet) Plateau. Sci. China Ser. D Earth Sci. 1996, $39,410-417$.

32. Vermote, E. MOD09A1 MODIS/Terra Surface Reflectance 8-Day L3 Global 500m SIN Grid V006; NASA Land Processes Distributed Active Archive Center User Services and USGS Earth Resources Observation and Science (EROS) Center: Washington, DC, USA, 2015. [CrossRef]

33. Zhang, X.; Sun, S.; Yong, S.; Zhou, Z.; Wang, R. Vegetation Map of the People's Republic of China (1:1000000); Geology Publishing House: Beijing, China, 2007.

34. Cheng, M.; Jin, J.; Jiang, H. Strong impacts of autumn phenology on grassland ecosystem water use efficiency on the Tibetan Plateau. Ecol. Indic. 2021, 126, 107682. [CrossRef] 
35. Li, P.; Peng, C.; Wang, M.; Luo, Y.; Li, M.; Zhang, K.; Zhang, D.; Zhu, Q. Dynamics of vegetation autumn phenology and its response to multiple environmental factors from 1982 to 2012 on Qinghai-Tibetan Plateau in China. Sci. Total Environ. 2018, 637-638, 855-864. [CrossRef]

36. Hutchinson, M.F.; Xu, T. Anusplin Version 4.4 User Guide; Fenner School of Environment and Society, The Australian National University: Canberra, Australia, 2013.

37. Zhao, H.; Huang, W.; Xie, T.T.; Wu, X.; Xie, Y.W.; Feng, S.; Chen, F.H. Optimization and evaluation of a monthly air temperature and precipitation gridded dataset with a 0.025 degrees spatial resolution in China during 1951-2011. Theor. Appl. Climatol. 2019, 138, 491-507. [CrossRef]

38. Guo, B.B.; Zhang, J.; Meng, X.Y.; Xu, T.B.; Song, Y.Y. Long-term spatio-temporal precipitation variations in China with precipitation surface interpolated by ANUSPLIN. Sci. Rep. 2020, 10, 81. [CrossRef] [PubMed]

39. Ge, Q.; Dai, J.; Cui, H.; Wang, H. Spatiotemporal Variability in Start and End of Growing Season in China Related to Climate Variability. Remote Sens. 2016, 8, 433. [CrossRef]

40. Jin, J.; Ying, W.; Zhen, Z.; Magliulo, V.; Min, C. Phenology Plays an Important Role in the Regulation of Terrestrial Ecosystem Water-Use Efficiency in the Northern Hemisphere. Remote Sens. 2017, 9, 664. [CrossRef]

41. Zhou, J.; Jia, L.; Menenti, M. Reconstruction of global MODIS NDVI time series: Performance of Harmonic Analysis of Time Series (HANTS). Remote Sens. Environ. 2015, 163, 217-228. [CrossRef]

42. Oksanen, J.; Blanchet, F.G.; Friendly, M.; Kindt, R.; Legendre, P.; McGlinn, D.; Minchin, P.; O’Hara, R.B.; Simpson, G.; Solymos, P. Vegan: Community Ecology Package (CRAN). R Package Version. 2015. Available online: https://CRAN.R-project.org/ package $=$ vegan (accessed on 27 July 2020).

43. R Core Team. R: A Language and Environment for Statistical Computing; R Foundation for Statistical Computing: Vienna, Austria, 2019.

44. Buttigieg, P.L.; Ramette, A. A guide to statistical analysis in microbial ecology: A community-focused, living review of multivariate data analyses. FEMS Microbiol. Ecol. 2014, 90, 543-550. [CrossRef]

45. Legendre, P.; Legendre, L. Canonical analysis. In Developments in Environmental Modelling; Legendre, P., Legendre, L., Eds.; Elsevier: Amsterdam, The Netherlands, 2012; Volume 24, pp. 625-710.

46. Tsai, H.P.; Lin, Y.-H.; Yang, M.-D. Exploring Long Term Spatial Vegetation Trends in Taiwan from AVHRR NDVI3g Dataset Using RDA and HCA Analyses. Remote Sens. 2016, 8, 290. [CrossRef]

47. Lepš, J.; Šmilauer, P. (Eds.) Basics of Gradient Analysis. In Multivariate Analysis of Ecological Data Using CANOCO 5, 2nd ed.; Cambridge University Press: Cambridge, UK, 2014; pp. 50-70.

48. Center, N.C. Blue Book on Climate Change in China; National Climate Center: Beijing, China, 2019.

49. Chen, X.; An, S.; Inouye, D.W.; Schwartz, M.D. Temperature and snowfall trigger alpine vegetation green-up on the world's roof. Glob. Chang. Biol. 2015, 21, 3635-3646. [CrossRef] [PubMed]

50. Liu, L.; Zhang, X.; Donnelly, A.; Liu, X. Interannual variations in spring phenology and their response to climate change across the Tibetan Plateau from 1982 to 2013. Int. J. Biometeorol. 2016, 60, 1563-1575. [CrossRef] [PubMed]

51. Cheng, M.; Jin, J.; Zhang, J.; Jiang, H.; Wang, R. Effect of climate change on vegetation phenology of different land-cover types on the Tibetan Plateau. Int. J. Remote Sens. 2018, 39, 470-487. [CrossRef]

52. Zhang, G.; Zhang, Y.; Dong, J.; Xiao, X. Green-up dates in the Tibetan Plateau have continuously advanced from 1982 to 2011. Proc. Natl. Acad. Sci. USA 2013, 110, 4309-4314. [CrossRef]

53. Ganjurjav, H.; Gao, Q.; Schwartz, M.W.; Zhu, W.; Liang, Y.; Li, Y.; Wan, Y.; Cao, X.; Williamson, M.A.; Jiangcun, W.; et al. Complex responses of spring vegetation growth to climate in a moisture-limited alpine meadow. Sci. Rep. 2016, 6, 23356. [CrossRef]

54. Flanagan, L.B.; Syed, K.H. Stimulation of both photosynthesis and respiration in response to warmer and drier conditions in a boreal peatland ecosystem. Glob. Chang. Biol. 2011, 17, 2271-2287. [CrossRef]

55. Wu, X.; Liu, H. Consistent shifts in spring vegetation green-up date across temperate biomes in China, 1982-2006. Glob. Chang. Biol. 2013, 19, 870-880. [CrossRef]

56. Shen, M.; Tang, Y.; Jin, C.; Xi, Y.; Cong, W.; Cui, X.; Yang, Y.; Han, L.; Le, L.; Du, J. Earlier-Season Vegetation Has Greater Temperature Sensitivity of Spring Phenology in Northern Hemisphere. PLoS ONE 2014, 9, e88178. [CrossRef]

57. Liu, Q.; Fu, Y.H.; Zeng, Z.; Huang, M.; Li, X.; Piao, S. Temperature, precipitation, and insolation effects on autumn vegetation phenology in temperate China. Glob. Chang. Biol. 2016, 22, 644-655. [CrossRef]

58. Yu, F.; Price, K.P.; Ellis, J.; Shi, P. Response of seasonal vegetation development to climatic variations in eastern central Asia. Remote Sens. Environ. 2003, 87, 42-54. [CrossRef]

59. Ren, S.; Yi, S.; Peichl, M.; Wang, X. Diverse Responses of Vegetation Phenology to Climate Change in Different Grasslands in Inner Mongolia during 2000-2016. Remote Sens. 2018, 10, 17. [CrossRef]

60. Piao, S.; Friedlingstein, P.; Ciais, P.; Viovy, N.; Demarty, J. Growing season extension and its impact on terrestrial carbon cycle in the Northern Hemisphere over the past 2 decades. Glob. Biogeochem. Cycles 2007, 21, GB3018. [CrossRef]

61. Wang, C.; Guo, H.; Zhang, L.; Liu, S.; Qiu, Y.; Sun, Z. Assessing phenological change and climatic control of alpine grasslands in the Tibetan Plateau with MODIS time series. Int. J. Biometeorol. 2015, 59, 11-23. [CrossRef] [PubMed]

62. Seddon, A.W.R.; Macias-Fauria, M.; Long, P.R.; Benz, D.; Willis, K.J. Sensitivity of global terrestrial ecosystems to climate variability. Nature 2016, 531, 229-232. [CrossRef] 
63. Jin, J.J.; Ma, X.; Chen, H.; Wang, H.; Kang, X.; Wang, X.; Wang, Y.; Yong, B.; Guo, F. Grassland production in response to changes in biological metrics over the Tibetan Plateau. Sci. Total Environ. 2019, 666, 641-651. [CrossRef]

64. Cong, N.; Piao, S.; Chen, A.; Wang, X.; Lin, X.; Chen, S.; Han, S.; Zhou, G.; Zhang, X. Spring vegetation green-up date in China inferred from SPOT NDVI data: A multiple model analysis. Agric. For. Meteorol. 2012, 165, 104-113. [CrossRef]

65. Chen, J.; Jönsson, P.; Tamura, M.; Gu, Z.; Matsushita, B.; Eklundh, L. A simple method for reconstructing a high-quality NDVI time-series data set based on the Savitzky-Golay filter. Remote Sens. Environ. 2004, 91, 332-344. [CrossRef]

66. Tian, J.; Zhu, X.; Chen, J.; Wang, C.; Shen, M.; Yang, W.; Tan, X.; Xu, S.; Li, Z. Improving the accuracy of spring phenology detection by optimally smoothing satellite vegetation index time series based on local cloud frequency. ISPRS J. Photogramm. Remote Sens. 2021, 180, 29-44. [CrossRef]

67. Peng, D.; Wang, Y.; Xian, G.; Huete, A.R.; Huang, W.; Shen, M.; Wang, F.; Yu, L.; Liu, L.; Xie, Q.; et al. Investigation of land surface phenology detections in shrublands using multiple scale satellite data. Remote Sens. Environ. 2021, 252, 112133. [CrossRef]

68. Wang, Y.; Luo, Y.; Shafeeque, M. Interpretation of vegetation phenology changes using daytime and night-time temperatures across the Yellow River Basin, China. Sci. Total Environ. 2019, 693, 133553. [CrossRef]

69. Piao, S.; Tan, J.; Chen, A.; Fu, Y.H.; Ciais, P.; Liu, Q.; Janssens, I.A.; Vicca, S.; Zeng, Z.; Jeong, S.-J.; et al. Leaf onset in the northern hemisphere triggered by daytime temperature. Nat. Commun. 2015, 6, 6911. [CrossRef] [PubMed]

70. Chai, X.; Shi, P.; Song, M.; Zong, N.; He, Y.; Li, Y.; Zhang, X.; Liu, Y. The relative controls of temperature and soil moisture on the start of carbon flux phenology and net ecosystem production in two alpine meadows on the Qinghai-Tibetan Plateau. J. Plant Ecol. 2020, 13, 247-255. [CrossRef]

71. Luo, M.; Meng, F.H.; Sa, C.L.; Duan, Y.C.; Bao, Y.H.; Liu, T.; De Maeyer, P. Response of vegetation phenology to soil moisture dynamics in the Mongolian Plateau. CATENA 2021, 206, 105505. [CrossRef]

72. Cleverly, J.; Eamus, D.; Coupe, N.R.; Chen, C.; Maes, W.H.; Li, L.H.; Faux, R.; Santini, N.S.; Rumman, R.; Yu, Q.; et al. Soil moisture controls on phenology and productivity in a semi-arid critical zone. Sci. Total Environ. 2016, 568, 1227-1237. [CrossRef] [PubMed]

73. Yang, Z.; Du, Y.; Shen, M.; Jiang, N.; Liang, E.; Zhu, W.; Wang, Y.; Zhao, W. Phylogenetic conservatism in heat requirement of leaf-out phenology, rather than temperature sensitivity, in Tibetan Plateau. Agric. For. Meteorol. 2021, 304-305, 108413. [CrossRef]

74. Cong, N.; Shen, M.; Piao, S.; Chen, X.; An, S.; Yang, W.; Fu, Y.H.; Meng, F.; Wang, T. Little change in heat requirement for vegetation green-up on the Tibetan Plateau over the warming period of 1998-2012. Agric. For. Meteorol. 2017, 232, 650-658. [CrossRef]

75. Shen, M.; Jiang, N.; Peng, D.; Rao, Y.; Huang, Y.; Fu, Y.H.; Yang, W.; Zhu, X.; Cao, R.; Chen, X.; et al. Can changes in autumn phenology facilitate earlier green-up date of northern vegetation? Agric. For. Meteorol. 2020, 291, 108077. [CrossRef]

76. Fan, J.L.; Wu, L.F.; Zhang, F.C.; Xiang, Y.Z.; Zheng, J. Climate change effects on reference crop evapotranspiration across different climatic zones of China during 1956-2015. J. Hydrol. 2016, 542, 923-937. [CrossRef] 